\title{
The effectiveness of a performance
management system at a South African \\ The effectiveness of a performance
management system at a South African public hospital in Cape Town
}

\begin{tabular}{|c|c|}
\hline \multicolumn{2}{|c|}{$\begin{array}{l}\text { Authors: } \\
\text { Baxolele Tyokwe }{ }^{1} \text { @ } \\
\text { Visvanathan Naicker }{ }^{1} \text { ( }\end{array}$} \\
\hline \multicolumn{2}{|c|}{$\begin{array}{l}\text { Affiliations: } \\
{ }^{1} \text { Faculty of Business and } \\
\text { Management Sciences, } \\
\text { Cape Peninsula University } \\
\text { of Technology, Cape Town, } \\
\text { South Africa }\end{array}$} \\
\hline \multicolumn{2}{|c|}{$\begin{array}{l}\text { Corresponding author: } \\
\text { Baxolele Tyokwe, } \\
\text { baxoleletyokwe@ } \\
\text { rocketmail.com }\end{array}$} \\
\hline \multicolumn{2}{|c|}{$\begin{array}{l}\text { Dates: } \\
\text { Received: } 21 \text { Sept. } 2020 \\
\text { Accepted: } 05 \text { Mar. } 2021 \\
\text { Published: } 12 \text { May } 2021\end{array}$} \\
\hline \multicolumn{2}{|c|}{$\begin{array}{l}\text { How to cite this article: } \\
\text { Tyokwe, B. \& Naicker, V., } \\
\text { 2021, 'The effectiveness of a } \\
\text { performance management } \\
\text { system at a South African } \\
\text { public hospital in Cape } \\
\text { Town', Africa's Public Service } \\
\text { Delivery and Performance } \\
\text { Review 9(1), a498. https:// } \\
\text { doi.org/10.4102/apsdpr. } \\
\text { v9i1.498 }\end{array}$} \\
\hline \multicolumn{2}{|c|}{$\begin{array}{l}\text { Copyright: } \\
\text { (c) 2021. The Authors. } \\
\text { Licensee: AOSIS. This work } \\
\text { is licensed under the } \\
\text { Creative Commons } \\
\text { Attribution License. }\end{array}$} \\
\hline \multicolumn{2}{|c|}{ Read online: } \\
\hline 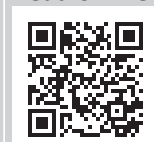 & $\begin{array}{l}\text { Scan this QR } \\
\text { code with your } \\
\text { smart phone or } \\
\text { mobile device } \\
\text { to read online. }\end{array}$ \\
\hline
\end{tabular}

Background: In 1994, South Africa instituted the Public Service Act of 1994 which is presumably applicable and must be adhered to by all public institutions. Because of the adoption of the Public Service Law, all employees employed in the Western Cape Government (WCG) are obligated to participate in the Performance Management System (PMS). Consequently, the authors were interested to know how the PMS performs and how employees respond to this system at a public hospital.

Aim: The purpose of this study was to examine the processes of PMS to identify its effectiveness. Of uttermost significance, through the findings of the study, was to make recommendations that contribute to improving the implementation of PMS.

Setting: The study is based at a public hospital to examine the effectiveness of a PMS at a South African public hospital. The hospital is situated in Cape Town, South Africa.

Methods: In pursuing the study, the authors employed an exploratory research design. Consequently, a qualitative research method was applied.

Results: The study discovered that the PMS at the hospital is ineffective to enhance the performance of the employees and achieve organisational goals.

Conclusion: The system appears to be a great tool designed to measure the employees' effectiveness. However, its implementation seems to suggest a need for a thorough investigation of its efficiency.

Keywords: appraisal; effectiveness; incentives; ineffective; performance; PMS; SPMS; unfairness.

\section{Introduction}

The study was initiated to examine the effectiveness of a Performance Management System (PMS) at a South African public institution in Cape Town, and the hospital was identified as a research site for the study. The study was not conducted in all departments of the hospital; it was conducted only at the stores and asset management unit. The authors were interested to know how the PMS performs and how employees respond to this system at the hospital. The intention was to ascertain whether employees in the hospital are satisfied with how PMS is implemented. The PMS at the hospital is popularly known as the Staff Performance Management System (SPMS) amongst employees as well as authorities of the Western Cape Department of Health.

Based on previous studies, the PMS appears to be a great tool designed to measure employees' performance and effectiveness to keep employees highly motivated to achieve organisational goals and the goals of the employees. Similar studies about PMS have been conducted by few individuals in various institutions in South Africa and elsewhere. For instance, one of the similar studies was conducted in Ireland by Farrell (2013) at an Irish Consumer Services Company. Here in South Africa, the same subject was investigated by Hendricks (2015), amongst others, at the Department of Rural Development and Land Reform in the Western Cape province. Although these studies occurred in different countries on either side of the world, they, however, have significant similarities which will be more evident as the literature review selected for this study.

\section{Background to the research problem}

Before 1994, there was no clear policy where the workplace concerned would in particular address the effective performance of employees and relevant incentives for outstanding performance. In 1996, the new Constitution of the Republic of South Africa was adopted. 
The Constitution of the Republic of South Africa (Republic of South Africa 1996: Section 195, Chapter 10) stated that:

$[P]$ ublic administration must be governed by democratic values and principles, amongst others to promote and maintain high standards of professional ethics, efficient, economic and effective utilisation of resources, and the cultivation of good human resource management and career development practices to maximize the human potential. (p. 99)

A lot had to be performed to get where South Africa's workplace is today, which includes implementation of PMS as a way to incentivise employees based on their performance at work. In 2001, the Public Service Regulations were amended to cover performance management at the national and provincial levels (Department of Public Service and Administration 2001).

However, studies suggest that PMS is unfair, where incentives and promotions depend on the personal relationships of employees with their direct supervisors (Khauoe, Joubert \& Karodia 2015). Unfairness appeared as a problem for PMS, and this influenced the authors to embark on the study to examine the effectiveness of the said system in the public institution.

The authors observed that PMS is an old system, and that it was working well when it was first initiated. According to Matunge (2013), PMS was first recorded in the 1800s by Robert Owen in New Lanark, Scotland. Owen created the system merely to assess the daily performance of his employees. After successful implementation, Owen was impressed with the results of the system. The employees were also excited, and their behaviours were improving daily. As the system was working, Owen decided to expand the application of the system to other aspects in the workplace and that is where he decided to evaluate and increase the salaries of the employees based on the performance of each employee. In the 1950s, the system became well-known globally.

In the 1950s, the United States started to link the system strategically with the vision and objectives of organisations. The system was also used for the motivation and development of employees. As cited by Matunge (2013), this process assisted in improving employees' passion for their work, especially the inclusion of an incentive as a way to encourage those working hard to work harder and those who are not performing well to strive to do better.

The authors selected Tygerberg Hospital as a site for this study because, to the best of the authors' knowledge, a similar study has never been conducted there before. The authors hypothesised that the results and findings that were determined in the previous studies could be true and could be affecting employees at the hospital, as well. Hence, there was a need to conduct this study. The authors were determined to contribute to this area, because PMS is a broad and important issue that is worth investigating for the benefit of the workplace, employers and the employees. The authors believed that previous researchers such as Khauoe et al. (2015) who conducted a similar study left a gap to explore. The gap to explore is still available because various institutions are using the PMS and research was never conducted in all those institutions to determine whether the said system is effective or ineffective for the institution.

\section{Purpose of the study}

The significance of this study was to examine the processes of SPMS at Tygerberg Hospital to identify its effectiveness. The intention was to ascertain whether employees in the hospital were satisfied with how SPMS is implemented. The authors intended to find out enablers where it was working well and disablers or barriers where it was less effective. Of uttermost significance, through the findings of this study, was to make recommendations that contribute to improving the implementation of SPMS. Also, the study offers guidance lead by the findings of this study, where necessary. There was a hope and belief that this study will provide a sound contribution to the institution to either change processes that are not working or sustain what is working and improve certain areas that might not be working well.

\section{Research objectives}

The objectives of this study are to:

- Identify the effectiveness of SPMS in improving the regular performance of the employees.

- Identify procedures and policies that are used when implementing SPMS.

- Make recommendations where necessary to improve what is not working well and sustain what is working well to offer the best execution of the system at the hospital.

\section{Research questions}

The main research questions for the study are as follows:

- What is the impact of SPMS in improving the regular performance of the employees?

- What are the procedures that must be performed or adhered to during SPMS processes?

- What are the views and experiences that employees have regarding SPMS?

\section{Empirical review}

The authors observed and drew an empirical review to ensure that the study is in line with other previous similar studies. Previous studies served as a point of reference in this article where applicable.

Bintu (2014) conducted a similar study and determined that performance appraisal existed in the 20th century to evaluate the performance of the employees, but back then it was performed secretively. The performance assessments of the employees were conducted behind closed doors, and employees were not permitted to contribute to discussions, 
meaning that the system was not transparent enough. He added that the processes of the system only changed in the mid-1900s, where the organisations started to discard the closed-door system and started to involve employees in the processes. And, after the implementation of the new idea of including employees in discussions, the system became more results-oriented. Employees began to recognise the system. Accordingly, Farrell (2013) stated that nowadays PMS is common in various organisations. Farrell cited that many organisations applied the system to evaluate performance and identify the weaknesses of the employees to equip employees with the necessary skills. During the implementation of the system, supervisors are responsible for giving accurate feedback and to guide employees about how and where to improve low performances. Of importance, Farrell (2013) points out that the system motivates and educates employees about the importance of meeting stated targets in the given period. Additionally, Nejati (2009) stated that the system helps management to strengthen the relationship between employees and managers to close the gap caused by the misunderstanding that might exist between these two parties. The PMS processes reduce dissatisfaction and the high number of grievances lodged by employees against the employers.

Furthermore, Matunge (2013) maintained that performance appraisal assists in planning for the future. The system allows managers to understand the priorities and plans of each employee in the organisation. The managers acquire awareness of whom the organisation should invest in more. Matunge (2013) added that performance appraisal works as a tool to inform management about when to hire or who to promote or dismiss because of their lack of performance. The system assists management in knowing how many employees need training. Paile (2012) concurred with the above scholars. He stated that the PMS was indeed created to guide and support employees to carry out their specified duties more effectively and efficiently to achieve the objectives and needs of the organisation. The performance appraisal is an instrument of sharing the vision of the organisation amongst all employees. The appraisals helped employees to understand the importance of their contribution to the firm which leads them to work harder.

Grobler et al. (2011) identified that PMS promotes good productivity in organisations because the system influences employees to work harder when implemented correctly. Furthermore, Grobler et al. (2011) added that PMS enables organisations to achieve high returns. The system assists organisations to move towards a results-orientated culture to achieve good production. The system inspires and provides satisfaction to employees with the available incentives and when employees are satisfied, they provide quality services.

The performance appraisal systems provide management with an opportunity to give feedback to the employees. The feedback helps to remedy poor performance and influences employees to work harder. The system increases ways of interaction between employees and managers to work together effectively.

Performance appraisal systems serve as a mechanism to assist organisations in communicating and reinforcing the values, norms and objectives of the institution. Regular communication and reinforcement of the values allow employees to be consistent in their performance to accomplish the desired results that are agreed upon (Faseeh ullah Khan 2013). Also, Paile (2012) stated that the continuous communication between supervisors and employees allows both parties to share information about performance progress and difficulties that employees experience in the workplace which helps management to understand what employees are going through. Paile (2012) added that communication helps supervisors to understand employees' needs and helps them search for suitable ways of working as a team to prevent poor performance and any other unnecessary problems that could occur in the future.

Asha (2007) stated that information collected from performance reviews helps to examine the necessity of recruitment and promotion of employees within the organisation. Managers during performance reviews can easily identify if the existing employees in the organisation are still adequate to do the job successfully or not. The decision of hiring extra employees can be determined by the quality of work presented by the employees.

The PMS enables managers to identify a shortage of skills in the organisation. Through the processes of the PMS, managers can identify when employees are unfit for the position. Managers can recognise if employees are willing and able to handle huge responsibilities and handle tough situations in the workplace. Paile (2012) stated that through performance appraisal processes, employees who displayed satisfactory performance regularly receive a salary increase. He explained that tangible incentives such as salary increases and cash bonuses encourage employees to keep on working hard for their recognition and own benefits. Also, Khauoe et al. (2015) concurred with the above statement; he stated that if outstanding performance is rewarded with extra bonuses, employees will always ensure that the job be completed effectively. Organisations should continue to provide sufficient rewards that are valued by employees to encourage quantity and quality execution of tasks that employees signed up for in their work contracts.

In contrast, the system was working well when it was first implemented and still yielded good results for some organisations when implemented correctly, but it is conflicted by many challenges as revealed by many scholars. For instance, Khauoe et al. (2015) found that the system is biased towards a majority of employees.

The incentives of the system such as performance bonuses and promotions depend on the personal relationships that employees have with their direct supervisors. Khauoe et al. (2015) explained that supervisors, when scoring the 
performance of the employees, are inconsistent. Similarly, Grobler et al. (2011) stated that inconsistent performance rating is a common problem of the system which occurs during performance assessments because of the fear and lack of knowledge on the supervisors' side. Grobler et al. (2011) stated that managers have a tendency of compromising policies and procedures that guide processes of the PMS and execute the system as they wish. Managers have a common problem of giving employees an average score or just give high scores only to those employees who are difficult to deal with, to keep them happy.

Furthermore, Noe et al. (2008) stated that the PMS is often clouded by issues of conflict amongst employees which lead to low energy and lack of cooperation in the entire workplace. Noe et al. (2008) further stated that managers do not enjoy using PMSs, but they do because they are obliged to carry out the process. On this point, Noe et al. (2008) stated that managers are uncomfortable and unwilling to inform employees about their poor performances, as that may lead to a confrontation which they feel less equipped for and unnecessary.

Richards (2012) stated that managers and supervisors in various organisations have little knowledge about how to conduct performance assessments accurately. Supervisors always fail to give appropriate feedback to all subordinates. Matunge (2013) stated that employees perceive the performance appraisal as a waste of time because the system does not influence them to improve their performances. After all, it does not contribute to employees' career growth. Matunge (2013) added that the performance appraisal system is not realistic. The system does not take into account some relevant legal issues. Employees are not involved in the development of performance appraisal. Employees do not have any idea about how their performance is evaluated and measured. The only employees who are the beneficiaries of the incentives of performance appraisal are those who have a close and loyal relationship with the supervisors which implies favouritism.

According to Redman and Wilkinson (2009), the system is expensive because it involves several processes that cost organisations fortunes. The processes consume and waste much time which could be invested in the production for more revenue. The system is also causing conflicts amongst employees and supervisors. The work relationship between employees and supervisors becomes poor. As a result, most employees do not recognise the system. Employees argued that the system is unfair and only favours certain individuals in the organisation. Some employees who have a long service record in the organisation have never received or enjoyed the fruits of the system, and only a few employees receive the incentives. The system discourages and eliminates the high morale of the employees. They drop their normal performance and level of commitment in the process. Employees feel neglected by their immediate supervisors. The application of the system is not clear. Ethical procedures are disregarded (Redman \& Wilkinson 2009). Paile (2012) agreed with the above scholars and stated that the incompetence of managers destroys the effectiveness of PMSs. Paile (2012) continued to say that managers should have the expertise and vast experiences to be able to perform fair assessments. Paile (2012) suggested that top management of organisations should decide on simple ways of evaluating and appraising the effective performance of employees rather than complicated ones. Managers fail to communicate the standard measures and to inform employees about what is expected from them.

Having discussed the above, it becomes evident that the findings of the study could be quite diverse. This is an indication that the findings of the study could go either way, maybe against or in favour of the system but ultimately all depends on how an institution prepares its employees and how they implement the system. The information discussed above is relevant and sufficient to understand what could occur when a PMS is executed well and when the system is not executed well. This literature review is important for the study and it is very informative because the employer who is in a position of implementing PMS in his or her organisation after reading this study may be able to plan and avoid negative outcomes that are identified and discussed above.

\section{Research methods and design}

The study applied a qualitative research method. Flick (2011) explained that the qualitative research method focuses on the analysis of data through words, which is what the authors desired to do. Also, Hendricks (2015) stated that the qualitative research method provides a researcher with an opportunity to connect personally with participants and enable a researcher to stand in participants' shoes and understand the pain and struggle that participants feel when they deal with issues in the community or at work. In combination with a qualitative method, the researchers employed an exploratory design. An exploratory research design is a tool that provides extensive details, insight and a clear understanding of the phenomenon (Flick 2011). Furthermore, Burns and Grove (2001) stated that an exploratory research design enables researchers to largely acquire views, gain insights and learn new ideas. Therefore, an exploratory research design was relevant and suitable for this study.

The authors interviewed a maximum of 30 participants to ensure the efficiency, effectiveness and quality of the study and outcomes. The population of 30 participants includes senior administrative officers, administration officers, senior administrative clerks and general assistants. The selected population is made of individuals who were permanently employed at the hospital when the research took place. The study conducted individual semi-structured interviews through a survey questionnaire as a data collection tool to collect qualitative data. All the participants were asked the same questions. Semi-structured interviews are more fit to explore experiences, opinions and individual views on various matters (Ryklief 2017). Furthermore, 
Hendricks (2015) stated that a semi-structured interview is regarded as a qualitative method of questioning where the researcher provides a planned set of open questions for respondents. However, a semi-structured interview is not only limited to pre-arranged questions but also allows open discussions between a researcher and an interviewee where the interviewee can reveal or raise issues that a researcher did not take into consideration. During the interview, participants were requested to answer open-ended questions. All the participants were given enough time to answer the questions. The researchers offered an explanation and clarity where there were misunderstandings.

The content analysis was used to interpret the unstructured data. The content analysis allowed the researchers to provide extensive details, insight and a clear understanding of the subject. The researchers studied the data repeatedly. Subsequently, the unstructured data were analysed manually to create valid outcomes. Hendricks (2015) posited that in qualitative research, the researcher is obligated to read and analyse the received data in words, unlike in quantitative research where data analysis is conducted through numbers. Another scholar, Ryklief (2017), concurred with Hendricks (2015) by confirming that unstructured data for qualitative research can be analysed by performing content analyses.

\section{Ethical considerations}

Ethical approval for this study was granted by the Cape Peninsula University of Technology Research Ethics Committee (ref. no.: 2018FBREC610) on 16 October 2018 for B.T.'s research activities for their Master's of Business and Information Administration. The researchers adhered to ethical considerations and maintained the highest standard of ethics to ensure that the findings of this study are valid, legitimate and beneficial to others. The consent to conduct this research at the hospital was granted by the head of the institution. The participants were informed about ethical considerations and the purpose of the study. The participants consented to participate and contribute to the study and allowed the authors to make use of their responses.

\section{Data presentation and analysis}

The participants were asked 10 questions in total, and the responses revealed the dominance of negative criticism towards the researched system, and only a few responses showed a good side about it. The first question posed to the participants was: 'How do you feel about the way the SPMS is conducted at Tygerberg Hospital?' This question intended to determine the individual feelings of the participants about the execution of the system. The authors believed that the participants would have a different perspective from how the system should be conducted against how it is conducted. The authors believed that proper execution of the system is crucial for the success of the SPMS. This means that if the system is implemented correctly, most of the employees would feel good and support the system. And therefore, if the system is conducted incorrectly, automatically the system would be ineffective because the majority would go against it.

Most of the participants are unsatisfied with the way SPMS is conducted in their respective departments. The participants complained about unfairness, duplication of the performance reports and lack of communication from the supervisors. Quoting direct responses of the participants, one of them stated that:

'I think SPMS at Tygerberg Hospital is conducted poorly and unprofessionally. Supervisors are not honest enough with employees, and they are not scoring the actual performance of the employees during the reviews, but I think they just give what is in their minds.' (Respondent $\mathrm{L}$, female, senior administartion clerk, 6-10 years' experience)

Similarly, another participant replied that:

'[S] upervisors perform the system incorrectly because people who are working hard, get [lower scores] of performance during performance evaluation but those who don't perform enough get high marks and that happens due to favouritism and ultimately they qualify for SPMS rewards.' (Respondent U, male, general assistant, more than 11 years' experience)

Furthermore, one of the participants stated that:

'I am very unhappy because supervisors do not say what is expected from us. They don't advise or inform us about our shortcomings, we have just given performance scores.' (Respondent R, male, senior administration clerk, 3-5 years' experience)

Seemingly, the lack of communication and favouritism appeared as a common problem in the processes of the system. For instance, Dechev (2010) identified that untrained supervisors always struggle to give proper feedback. He cited that supervisors' feedback is always obstructed by dishonesty. Out of 30 participants, only six participants were convinced with the way the system is conducted at the hospital. Although it is only limited to individuals who showed satisfaction about the system, still they suggested that there are gaps to be closed.

The second question posed to the participants was: 'What are the views and experiences that you have regarding SPMS?' This question was asked to give participants the freedom and fair chance to pour out their hearts to say anything that they observed and experienced during the execution of the SPMS at Tygerberg Hospital. It is fair to say that the experiences of the participants were terrible as they view the system as deceitful because of the way it is conducted by authorities. The respondents revealed that the execution of the system is performed inappropriately because only a few employees enjoy the incentives of the system repeatedly. The participants alluded that the system should be terminated, if not, the incentives should be shared equally amongst the employees. One of the participants stated that: 
'SPMS is imbalanced simply because there are employees who work very hard, but they do not get the rewards of cash bonus at the end of the performance cycle.' (Respondent $\mathrm{C}$, male, senior administration clerk, 6-10 years' experience)

\section{Another participant added that:}

'The number of people that deserve or qualify for SPMS cash bonus always exceeds the allocated budget. Seeing that everyone that qualifies for a cash bonus and yet cannot get it I feel like it should be taken away or rather give $[a]$ certain amount of money to everyone equally.' (Respondent B, male, administrative officer, more than 11 years' experience)

It is clear that the participants were unhappy and appeal for intervention and implementation of changes. And therefore, management should intervene as soon as possible to resolve the issues posed by the participants.

However, the views of the participants are not surprising because the literature review presented above showed that PMS is implicated by many challenges. For instance, some of the issues that were addressed by the participants are equal with those that were found by Khauoe et al. (2015) such as favouritism. Likewise, Richards (2012) found that managers lack the knowledge and experience to perform the system accurately, which could be the same problem that occurs at Tygerberg Hospital. Although the participants complained about unfairness, the Western Cape Government (WCG) as the employer condemns unfairness in all processes of the SPMS. The government stated that employees and supervisors should have joint discussions and reach a mutual consensus through transparency to avoid unfairness. The employer affirmed that SPMS is a consultative support and non-discriminatory process (Department of Health 2002). Therefore, if the claims of the participants are true, this means that management and supervisors are not complying with the policies and practices that are available.

The third question was as follows: 'How reasonable or unfair is the top management of the hospital in rewarding all hardworking employees equally?' The question was directed to top management because they are the decisionmakers and are in control of the budget and form part of SPMS committees. The authors wanted to determine if the employees understand the role of top management and how they observe the top management towards issuing incentives. Most importantly, the authors were interested to know if the incentives are distributed fairly and if employees are satisfied. According to responses, the respondents were not pleased with the distribution of the performance rewards. A huge number of the participants blamed the top management for all the injustice that they experienced. Amongst other things that participants accused top management of are unfairness, favouritism and lack of communication. Even though supervisors do not form part of top management, they were implicated as well for unfairness. Supervisors were also accused of duplication of performance reports and invisibility in the workstations. For instance, one of the participants mentioned that:
'The system can be manipulated, and anyone in high [higher] level can influence the results of the system.' (Respondent $\mathrm{H}$, male, senior administration clerk, 6-10 years' experience)

Also, one of the participants responded that:

'Top management do not monitor the execution and processes of SPMS regularly to ensure that the system is implemented properly and fairly.' (Respondent L, female, senior administration clerk, 6-10 years' experience)

Similarly, another participant stated that:

'Only those that [who] are favoured get SPMS cash bonuses, so that is unfair to other employees who always go the extra mile but not being recognised.' (Respondent J, female, senior administration clerk, 3-5 years' experience)

The direct quotes that are cited above prove that most of the employees are not satisfied with the distribution of the incentives. In contrast, only two participants were in favour of the top management in the distribution of the incentives. One of the participants who were in favour mentioned that:

'Top management try their best by taking one bonus and give it to two people and give both people an accelerated pay progression.' (Respondent B, male, administrative officer, more than 11 years' experience)

Thus, some employees are happy with the top management in distributing incentives but there are few.

The fourth question was as follows: 'How do you perceive the measurements that are used to score performance at the hospital?' According to the literature review presented above, the performance of the employees had to be evaluated but Grobler et al. (2011) stated that when managers evaluate the performance of employees, they have a common problem of giving employees an average score or just give high scores only to those employees who are difficult to deal with, to keep them happy. The responses showed that the participants were unhappy with the measurement tools that are used to rate the performance of the employees at Tygerberg Hospital. The responses revealed that the performance rating method used at Tygerberg Hospital is not genuine. The performance of employees at Tygerberg Hospital is measured against proof of evidence collected and submitted by the employees. The participants have a big problem with the collection of evidence, and they do not consider the collection of evidence as valid as it should be because it can be provided by anyone. According to the views of the participants, performance scoring should be based solely on the accomplishment of the core duties that are set on the performance plan and job description. The participants believed that supervisors should evaluate and assess how good or bad the outcomes have been achieved and then provide a suitable score without counting the quantity of the evidence submitted. The participants argued that there is a high possibility of irregularities that can occur from the evidence collected from colleagues and external departments. The participants fear that some colleagues can create false evidence as there is no inspection of the evidence. 
Furthermore, the issue of incorrect application of performance ratings was also identified in previous studies. For instance, Khauoe et al. (2015) stated that the effectiveness of the system is damaged and destroyed by inconsistency in performance ratings. Therefore, management should, in order to sustain the effectiveness of the system, scrutinise the submitted evidence to avoid uncertainty from employees. Management should clarify the kind of evidence to be submitted, and they should also inform employees about where the evidence can be collected and who should collect the evidence. The clarity from management could bring confidence back from the employees.

The fifth question was as follows: 'What is the impact of SPMS in improving your regular performance?' According to Asha (2007), PMS has a great impact on keeping employees motivated and encouraging good morals. The compensation and recognition that employees receive for their extra effort make them feel a sense of worth and belonging in the organisation. Also, Faseeh ullah Khan (2013) stated that performance incentives add positive pressure on the employees. It encourages employees to achieve their targets faster. Employees become more determined to take more responsibilities at work as they will be compensated. In contrast, the participants argued that SPMS does not influence their work performance. Instead, it creates tension and bad competition amongst them. The responses revealed that the system ruins friendships and teamwork between employees and creates unnecessary tension. The participants stated that they are no longer assisting each other because of high disappointments and frustrations of SPMS rewards which are not received equally by all employees. The authors can confirm that SPMS does not encourage or improve the regular performance of the employees based on the collected data.

The sixth question was as follows: 'How do the performance rewards such as cash bonus and pay progression motivate you in your daily performance?' This question was specifically asking about the money that employees should receive through the implementation of the system. The authors were under the perception that the money could have a great influence in motivating employees to work harder towards achieving their targets and the objectives of the hospital. Previous studies confirmed that employees are likely to be motivated and improve their regular performance if performance rewards are solely based on great individual performance without preferential treatment to other employees (Vigaro 2013). Similarly, Faseeh ullah Khan (2013) determined that employees become inspired when they receive performance bonuses. Khauoe et al. (2015) cited that when organisations compensate great performance with extra bonuses, the employees often acquire the job completed effectively within the time limit. Consequently, he recommended that organisations should continue to provide sufficient rewards that are valued by employees to encourage quality work performance. However, the responses of the participants indicated that most of the participants are not influenced by money. The participants clearly stated that they are not influenced by incentives of SPMS to change or increase their normal standard of performance.
The participants believed that SPMS incentives at their respective departments are for certain individuals. By looking at the responses of the participants, it will be very difficult for the employer to achieve its objectives through SPMS until the management puts a close eye on the implementation and processes of the system.

The Constitution of the Republic of South Africa in Section 195(h) promotes good human resource management and career development of employees to be maximised and to cultivate human potential (Republic of South Africa 1996). Thus, all employees in the workplace in South Africa should have access to various development programs and pieces of training to maximise and cultivate the human potential as the Constitution of South Africa instructed. The above statement led the authors to ask participants the following question to determine if the career development of employees is considered and employees are benefitting because the system is linked with the skills development of employees according to the empirical review. The seventh question was as follows: 'What role or contribution does SPMS play in terms of skills development and employment promotions?' The responses portrayed that skills development and training programs for employees in stores and assets management are inadequate. The participants disputed that the SPMS contributes to their career growth. They unanimously stated that the SPMS does not contribute to their growth in the workplace. They confirmed that it only increases salary notches. Some participants discussed that even training that is supposed to help them grow is limited and mostly available for few employees such as interns. According to some of the responses, at the beginning of each financial year, employees are requested to list several courses that they would like to attend during the year. However, the financial year would normally come to an end without attending any of the identified training.

In similar studies, Grobler et al. (2011) mentioned that managers tend to compromise policies and procedures that guide processes of the PMSs and execute the system negligently. The eight question, which assisted the authors in understanding the processes of the system, was as follows, 'Which procedures are followed during implementation of the system?' The authors assumed that all the organisations using this system would have procedures and processes in place that are applied to the implementation of the system for its success. The question produced various responses, but most participants mentioned the collection of evidence as a common procedure that is normally followed during SPMS executions. For instance, one of the participants stated that:

'Employees are required to collect evidence from other departments for the work that they performed there to boost their scorings.' (Respondent L, female,senior administration clerk, 6-10 years' experience)

\section{Another participant added that:}

'The collection of evidence is essential, but the question is why employees must collect evidence, even though they meet their targets.' (Respondent R, male,general assistant, 3-5 years' experience) 
Furthermore, one of the participants argued that:

'Supervisors should come regularly to check what is done by employees to be able to write $[a]$ correct performance report. Currently, colleagues are asked [to] bring incidents from nurses but I believe that nurses just ask [for] assistance from Stores' employees because they are [mostly] females and for me that does not mean the person assisted is working hard by helping a nurse out.' (Respondent T, male, senior administration clerk, $3-5$ years' experience)

On the one hand, some of the participants mentioned the completion of the job description, performance plans and reviews that must take place quarterly during the year. On the other hand, some of the participants denied and failed to provide relevant procedures that apply to the processes of the SPMS.

The ninth question posed to participants was: 'How easy or difficult is it to apply SPMS processes and policies accurately?' The authors established that the participants have difficulties applying processes of the SPMS. Once again, the emphasis from the participants was on the issue of collecting the evidence. On top of that, the participants could not identify any other issue or a specific policy or process that prevents them to apply the processes accurately besides the collection of evidence. Participants stated that the application of the processes could be easy if there was no collection of evidence. Seemingly, the participants accept all other processes if any, but they refuse to collect evidence, especially outside their departments. The collection of proof for extra points is an obstacle for employees at the hospital to be able to reap the fruits of SPMS. And therefore, management should intervene and advise accordingly in this matter. Otherwise, this issue will continue to prevent the success of the SPMS.

The last question that the authors asked was as follows: 'What are the difficulties that you come across during the SPMS reviews?' The collection of evidence appeared as a core problem. The collection of evidence has a high potential of eliminating the effectiveness of the SPMS. A possible solution to the matter of collecting evidence is that management should come forward to explain and educate employees about why employees must collect evidence. Employees need to understand how the incidents fit into the SPMS processes and how the evidence contributes to their scores.

\section{Findings and discussions}

The study was intended to examine the effectiveness of the PMS at a South African public hospital, and Tygerberg Hospital was selected as a site of the study. The focus of the study was on the execution of the system and the satisfaction of the employees with the benefits that they should receive from the system once conducted. The authors wanted to know if the PMS has an impact on the employees' performance. The findings of this study are influenced and concluded specifically from responses of the participants and linked to the objectives of the study.

Ultimately, this study found that the PMS is ineffective at Tygerberg Hospital, particularly in stores and assets management to achieve the intended workplace objectives. For instance, the Public Service Act (1994) requires all government institutions to implement a PMS which will be consultative and non-discriminatory to all employees to improve the effectiveness and efficiency of the workplace.

However, the collected data showed that PMS is ineffective because it failed to improve effectiveness and efficiency in the selected departments. The participants observed PMS as an unfair system towards the majority of the employees. The ineffectiveness of the SPMS is the main finding of the study. The contributing factors to the ineffectiveness of the system were determined as follows: lack of skills development programs, inadequate training for employees, the imbalanced distribution of incentives and lack of motivation.

\section{Limitations}

Whilst the study was limited to two departments at Tygerberg Hospital and to 30 research participants, what was clear was that there were not enough academic materials for such a study. Adding to the challenges mentioned above, the unavailability of the respondents was one of the main challenges. The authors found the environment to be very hectic to conduct interviews. All the respondents were very busy, and it was awkward for them to attend the research meetings although the interviews were scheduled well in advance with them.

Some of the respondents were interrupted during the interviews when they were asked to attend to crucial matters immediately. Some of the respondents refused to be recorded during the interviews but the authors took minutes for some of the issues that emerged off the record and that was not recorded. As the respondents were very busy, some of them requested to answer the prearranged questions in the survey questionnaire during their spare time. And this appeared to be a research tool working for those who were not available for the interviews.

\section{Recommendations}

The recommendations were made based on findings yielded by responses to research questions and research objectives. The following recommendations intend to help management to address issues that need to be rectified and assist in solving the concerns and disputes that were presented by the participants.

The authors recommended that management should implement the provision of training and relevant workshops, promote skills development of employees, and improve fairness. The above three recommendations will help management restore the effectiveness of the SPMS. Also, the recommendations will assist management to perform the system constructively in the future to avoid possible complaints and disagreements that may arise. 
Concerning further research, there is still a gap demanding future researchers to expand on this study at the hospital because the authors did not cover the entire hospital. Future research needs to be extended to other departments of the hospital to determine the effectiveness or ineffectiveness of the system for the entire hospital. The hospital is a big institution that consists of many departments. The process could involve many different researchers taking selected areas of the hospital and undertaking different topics on this subject to acquire results that could help improve the entire institution.

\section{Conclusion}

In conclusion, the effectiveness of the PMS which is known as SPMS at Tygerberg Hospital was investigated.

The researchers collected literature relevant to the study to support the investigation to ensure that the study is relevant to other previous studies and paves a way for future research. Some of the literature revealed negative criticisms whilst other literature revealed the good side of the PMS. It is fair to say that the negative side is dominantly based on the responses of the respondents. Although the bad side of the PMS is dominant, some of the literature presented in the research showed that the PMS should encourage and strengthen the usual everyday performance of employees where they could reach optimal performance.

The study was conducted through a qualitative research method. The semi-structured interviews enabled the researchers to acquire a deeper perspective of the PMS on the two departments selected for the study. The 30 participants were selected in stores and asset management at the hospital and assisted the researchers to acquire the required information which made this study possible. The authors found through this study that the PMS is ineffective in the selected departments because it does not achieve the intended objectives. Evidence collected during interviews showed that employees are not benefitting from the processes of the system; instead they are getting hurt by the processes because the system favours few individuals. One of the principles of the PMS is fairness. However, the information collected from the participants of this research showed that the PMS is unfair, and it does not improve the regular performance of employees to greater levels of commitment.

The management of the hospital should take the findings of the study as a lesson to rectify what is happening inappropriately and improve what needs to be improved. As the findings indicate that SPMS is implicated with many problems and does not serve its main purposes, many amendments in the implementation of SPMS are a matter of urgency. As the intentions of this study were not to be a response to matters related to the implementation of the SPMS but to highlight some of the challenges related to its implementation, the authors hope that management will make recommendations and apply them where necessary.
Likewise, the authors hope that this study will contribute and assist the management of the hospital to resolve the issues as presented in the study. Management should strive to work towards ensuring that SPMS stays relevant and effective in the workplace.

\section{Acknowledgements}

B.T. wish to thank and acknowledge the following people:

My special wife Yonela Tyokwe. She believes in me more than I do. She allowed me to accomplish my individual dreams and desires. I thank her for the freedom of choice, freedom of movement and allowing our money to be invested in education. I thank her for allowing me to study further.

My supervisor Prof. Visvanthan Naicker. I really appreciate the valuable assistance and supervision that I received from Prof. Naicker. Without him, I definitely was not going to make it.

\section{Competing interests}

The authors declare that they have no financial or personal relationships that may have inappropriately influenced them in writing this article.

\section{Authors' contributions}

B.T. and V.N. contributed equally to this article.

\section{Funding information}

This research received no specific grant from any funding agency in the public, commercial or not-for-profit sectors.

\section{Data availability}

The authors confirm that the data supporting the findings of this study are available within the article.

\section{Disclaimer}

The views and opinions expressed in this article are those of the authors and do not necessarily reflect the official policy or position of any affiliated agency of the authors.

\section{References}

Asha, S., 2007, Psychological dimensions of training and development, Human Resource Management Review, ICFAI University, Telangana.

Bintu, S., 2014, 'Effectiveness of performance appraisal systems', Unpublished Master's thesis, Kwame Nkrumah University of Science and Technology.

Burns, N. \& Grove, S.K., 2001, The practice of nursing research: Conduct, critique and utilisation, 4th edn., WB Saunders, Philadelphia, PA.

Dechev, Z., 2010, 'Effectiveness performance appraisal', Unpublished Master's thesis, Erasmus University Rotterdam, Rotterdam.

Department of Health, 2002, Performance and development management procedural manual, Government Printers, Cape Town.

Department of Public Service and Administration, 2001, Public service regulations, Government Printers, Pretoria.

Farrell, A., 2013, 'An investigation into performance appraisal effectiveness from the perception of employees', Unpublished Master's thesis, National College of Ireland. 
Faseeh ullah Khan, M., 2013, 'Role of performance management system on employees motivation', Journal of the Business and Management 8(4), 66-83. https://doi. org/10.9790/487X-0846683

Flick, U., 2011, Introducing research methodology: A beginner's guide to doing a research project, Sage, London.

Grobler, A., Warnich, S., Carrel, R., Elbert, F. \& Hatfield, D., 2011, Human resource management in South Africa, 2nd edn., Thompson Learning, London.

Hendricks, C.C., 2015, 'The management of employee performance in the department of rural development and land reform in the Western Cape', Unpublished Master's thesis, Cape Peninsula University of Technology.

Khauoe, M.G., Joubert, P. \& Karodia, A.M., 2015, 'Evaluating the effectiveness of performance appraisals and the impact of performance remuneration on employees' motivation: A case study of a chemicals and waste management branch at the Department of Environmental Affairs (South Africa)', Singaporean Journal of Busines Economics and Management Studies 9(3), 10-44. https://doi.org/10.12816/0010977

Matunge, S., 2013, 'Employee perception on the effectiveness of performance appraisal system', Unpublished Master's thesis, University of Nairobi.

Nejati, M., 2009, Global business and management research: An international journal, vol. 1, no. 2, Universal Publishers, Boca Raton, FL.
Noe, A., Hollenbeck, R., Gerhart, B. \&Wright, M., 2008, Human resource management: Gaining a competitive advantage, 6th edn., McGraw-Hill, New York, NY.

Paile, N.J., 2012, 'Staff perceptions of the implementation of a performance management and development system', Unpublished Master's thesis, University of South Africa.

Redman, T. \& Wilkinson, A., 2009, Contemporary human resource management cases, Pearson Education, Harlow.

Republic of South Africa, 1994, Public Service Act, Government Printers, Pretoria.

Republic of South Africa, 1996, The Constitution of the Republic of South Africa, Act 108 of 1996, Government Printers, Pretoria.

Richards, A., 2012, Factors affecting the effectiveness of performance appraisal systems, Demand Media Publications, New York, NY.

Ryklief, M.Y., 2017, 'The equity composition of employees in a selected provincial government department in the Western Cape, South Africa', Unpublished Master's thesis, Cape Peninsula University of Technology.

Vigaro, M.R., 2013, 'An effective performance management system for selected company in the construction industry', Unpublished Master's thesis, Cape Peninsula University of Technology. 